\title{
Drummond's Milk Vetch
}

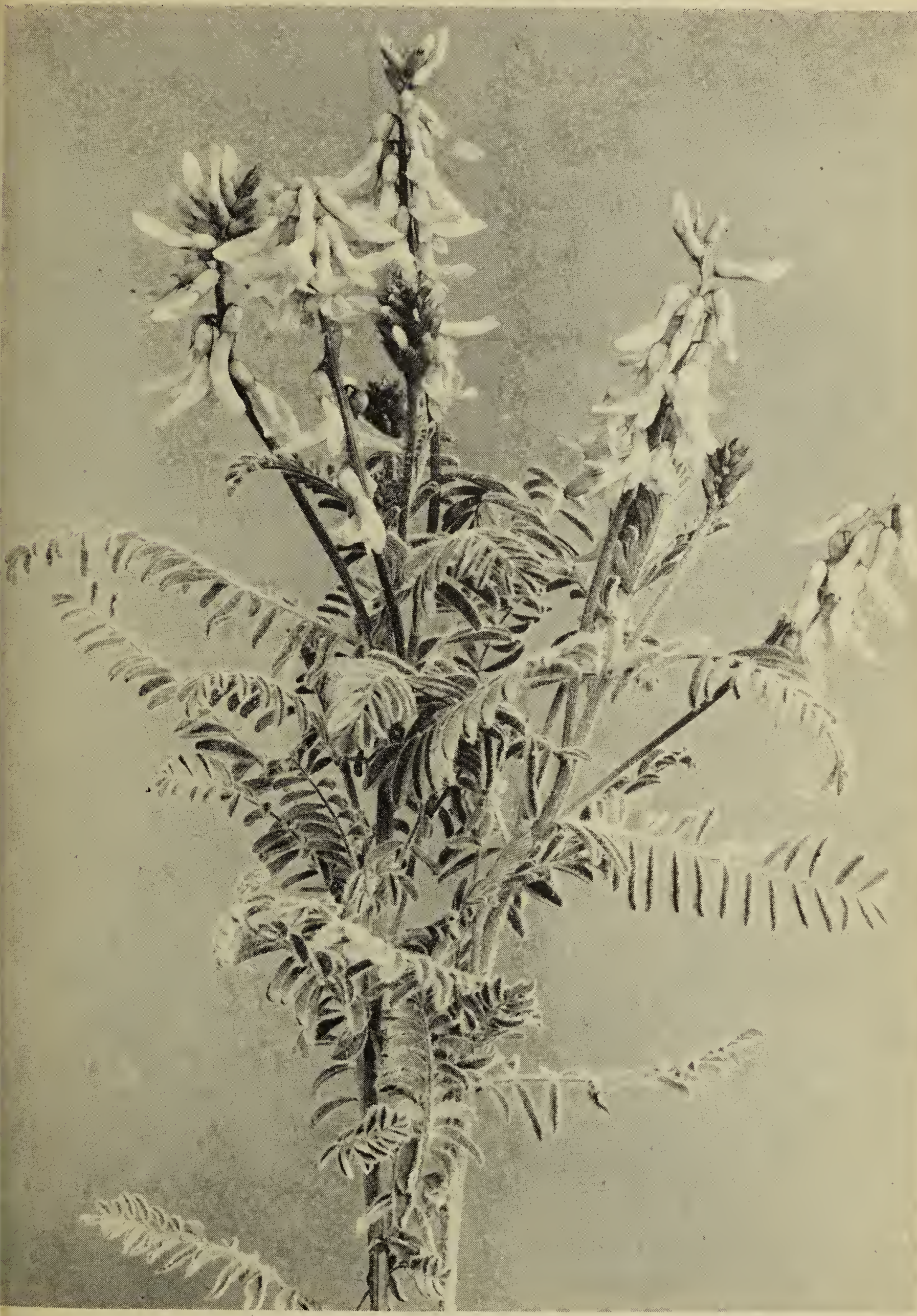

Photo by the late Dr. W. C. McCalla

Astragalus drummondii Dougl.

Drummond's Milk Vetch is a handsome species found growing on dry exposed hillsides and crairies in southwestern Saskatchewan and in Alberta. The stems grow in clumps and may be about two feet tall. The leaves are conspicuously white woolly. The flowers are a yellowish white and sometimes the keels are tinged with purple. 